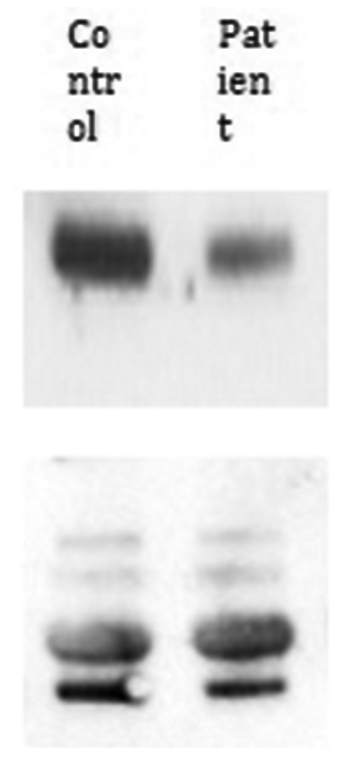

Abstract G477 Figure 2 PAR2 expression in serum from control and patient samples

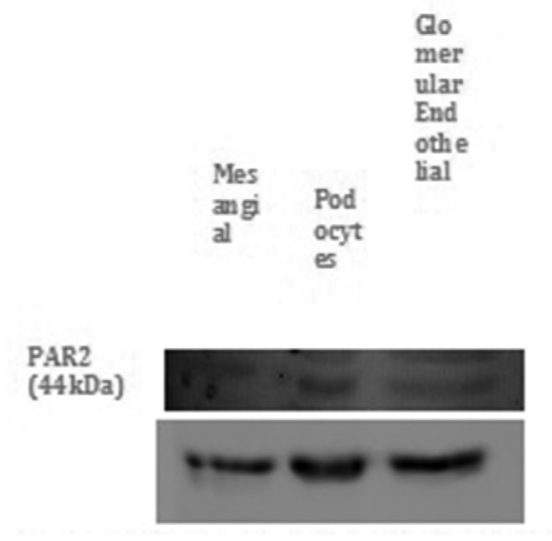

Abstract G477 Figure 3 PAR2 expression in immortalised kidney cells, demonstrating expression in wild-type endothelial,mesangial and podocyte cells

whether PAR2 represents a unique pathway in these rare renal phenotypes.

\section{G478(P) A CASE REPORT OF TRBETA MUTATION LEADING TO RAISED T4 LEVELS}

${ }^{1} \mathrm{~N}$ Tomlinson, ${ }^{2}$ Banerjee, ${ }^{3} \mathrm{~K}$ Chatterjee, ${ }^{1} \mathrm{TD}$ Smith, ${ }^{1} \mathrm{~A}$ Mukherjee. ${ }^{1}$ Royal Oldham Hospital, Pennine Acute Hospitals NHS Trust, Oldham, UK; ${ }^{2}$ Royal Manchester Children's Hospital, Manchester, UK; ${ }^{3}$ Cambridge University Hospitals, Cambridge, UK

10.1136/archdischild-2015-308599.432

Introduction We present a five year old girl with thyroid hormone resistance, subsequently discovered to be heterozygous for TRbeta mutation. This case highlights the necessity to investigate, in detail, all children with persistently high thyroxin with normal TSH levels in order to aid future management and the necessity to follow them up.

Case report The patient was born at term by normal delivery, weighing $3.34 \mathrm{~kg}$ (50th centile). She was referred at six months of age for poor weight gain (2nd centile). Blood tests showed an elevated free T4 (43.4) with normal TSH (3.10). Systemic examination was normal and remained so over the following months. Repeat thyroid function tests showed persistently elevated T4 with normal TSH. At $2 \frac{1}{2}$ years old, genetic analysis revealed she is heterozygous for TRbeta mutation (thyroid hormone receptive gene). Mum has no mutation detected and her father cannot be tested for unavoidable reason. Since then, she has had slow growth, idiopathic thrombocytopenic purpura, vitamin D deficiency, and coeliac disease. Broader antibody testing has not revealed an underlying autoimmune aetiology to date. Recently, the patient has been investigated for recurrent falls and abnormal gait. She has right sided hemi hypotrophy with drooped shoulder and pelvis, along with winged scapulae, flared ribs and prominent abdomen. Her gross motor skills are generally delayed.

Conclusion Mutation of the beta thyroid hormone receptor is usually either autosomal dominantly inherited or is a de novo mutation, resulting in defective patterns of gene expression. This is a rare disorder, usually presenting with goitre. TRbeta mutation should be considered in children with persistently elevated T4 levels in conjunction with a normal TSH. The other immune conditions like ITP and changes in body habitus are new associations, cause of which is yet not identified. * Photos are available **

\section{G479(P) ADHERENCE TO BLOOD GLUCOSE MONITORING IN CHILDREN AND YOUNG PEOPLE WITH TYPE 1 DIABETES ON INSULIN PUMP THERAPY IN A TEACHING HOSPITAL}

S Punniyakodi, PCB Sundaram, JE Greening, V Tziaferi. Paediatric Diabetes, University Hospitals of Leicester NHS Trust, Leicester, UK

10.1136/archdischild-2015-308599.433

Aims Children and young people with Type 1 diabetes on insulin pump therapy are expected to perform 4-8 capillary blood glucose (BG) tests per day for better glycaemic control. Our objective was to find out whether our patients adhered to the expected BG monitoring.

Methods Data was collected from 78 patients during a clinic visit over a period of one year. All children have glucometers which wirelessly transmits the data to their insulin pump. Average numbers of BG tests per day and mean BG levels were downloaded through the pump software for two weeks prior to their clinic visit.

Results 48 children (61.5\%) did 4-8 BG tests per day while 18 (23.1\%) did more than 8 tests. $12(15.4 \%)$ who did less than 4 per day had a mean age of 14.8 years. We found moderately significant negative correlation between age and frequency of BG testing (Pearson's correlation coefficient $(\mathrm{R})=-0.57$ ) and also number of BG tests and mean BG levels $(R=-0.52)$. There was a weak negative correlation between number of BG tests and HbA1c levels $(\mathrm{R}=-0.31) .5$ patients $(6.4 \%)$ entered fictitious BG levels manually into their pump and details are given in the table. 


\begin{tabular}{|c|c|c|c|c|c|c|}
\hline No & $\begin{array}{l}\text { Age } \\
\text { (Years) }\end{array}$ & $\begin{array}{l}\mathrm{HbA1c} \\
(\mathrm{mmol} / \mathrm{mol})\end{array}$ & $\begin{array}{l}\text { Average } \\
\text { number of } \\
\text { BG tests } \\
\text { per day } \\
\text { (Actually done) }\end{array}$ & $\begin{array}{l}\text { Average } \\
\text { number of } \\
\text { BG tests per } \\
\text { day (manual } \\
\text { entries) }\end{array}$ & $\begin{array}{l}\text { Mean BG } \\
\text { (mmol/L) }\end{array}$ & $\begin{array}{l}\text { Mean BG } \\
\text { after removal } \\
\text { of manual } \\
\text { entries (mmol/L) }\end{array}$ \\
\hline 1 & 13.4 & 66 & 2.4 & 1.2 & 11.3 & 12.3 \\
\hline 2 & 14.9 & 72 & 0.4 & 4.5 & 7.2 & 12.3 \\
\hline 3 & 15.1 & 65 & 4.7 & 3.1 & 8.8 & 10.6 \\
\hline 4 & 15.2 & 56 & 0.5 & 5.3 & 8.6 & 13.4 \\
\hline 5 & 16.2 & 69 & 3.1 & 1.6 & 10 & 11.6 \\
\hline
\end{tabular}

Conclusion $84.6 \%$ of patients adhered to the expected number of BG tests while a $15.4 \%$ did not. The negative correlation between the number of BG tests and mean BG levels confirms the importance of frequent $B G$ monitoring to improve glycaemic control. 6.4\% (mainly adolescents) were manually entering fictitious BG levels which offered false assurance to family and clinician. Diabetic teams should be aware of this and vigilant to detect noncompliance in adolescents on insulin pump and offer appropriate counselling.

\section{G480(P) CARBOHYDRATE COUNTING FROM DIAGNOSIS: IS IT PRACTICAL, ACCEPTABLE AND EFFECTIVE?}

TP Candler, S Blakey, S Matthai. Paediatrics, Gloucestershire Royal Hospital, Gloucester, UK

\subsection{6/archdischild-2015-308599.434}

Background Carbohydrate counting has become a principal strategy for children with type1 diabetes. Precision with carbohydrate counting are associated with lower HbA1C in children with type 1 diabetes (Mehta, 2009). Traditionally, children were not taught this during their first presentation with diabetes. In Gloucester and our network, carbohydrate counting is being taught from diagnosis to embed this practice early.

Aims With regards early carbohydrate counting education, we asked: is it practical? is it acceptable to families? is it effective?

Methods We compared two 12 month time periods 1/3/12-28/ $2 / 13$ (education delayed) and 1/3/13-28/2/14 (education early). A sample of 15 patients from both years had their notes and biochemistry results examined. A questionnaire about patient's experience of early carbohydrate counting was sent.

Results Comparing the two time periods (delayed vs. early); the mean age at diagnosis was 9.07 vs. 9.33 years, $36 \%$ vs. $47 \%$ of patients presented in DKA. The majority started on basal bolus regime but $14 \%$ vs. $7 \%$ of patients were started on a pump during first admission. There was no significant difference in length of stay (4.21 vs. 5.13 days, $\mathrm{p}=0.056$ ). Falls in HbA1C appear sustained across the early education group. 81\% learnt $\mathrm{CHO}$ counting within a week, $64 \%$ preferred to learn $\mathrm{CHO}$ counting in hospital and $100 \%$ found the education useful.

Conclusion Early education about carbohydrate counting appears both practical and effective. There was no increase in length of stay between the two groups. There was generally positive feedback from those families that had early $\mathrm{CHO}$ counting education.

\section{G481(P) INSIGHTS INTO FACTORS AFFECTING CHILDHOOD OBESITY IN UNITED KINGDOM MIGRANTS OF SOUTH ASIAN ORIGIN}

${ }^{1} \mathrm{LMC}$ Burland, ${ }^{2} \mathrm{H}$ Hassanzadeh, ${ }^{3} \mathrm{BL}$ Green. ${ }^{1}$ Department of Paediatrics, Bradford Teaching Hospital NHS Trust, Bradford, UK; ${ }^{2}$ Epsom and St Helier University Hospitals NHS Trust, Carshalton, UK; ${ }^{3}$ Leeds Teaching Hospitals NHS Trust, Leeds, UK

\subsection{6/archdischild-2015-308599.435}

Introduction Childhood obesity represents a significant threat to the health and wellbeing of future generations of adults in the United Kingdom (UK). Certain ethnic minorities including those of South Asian origin experience notably higher rates of childhood obesity. As the primary care-providers in South Asian culture, mothers play a significant role in determining child health: improved understanding of perceptions regarding childhood obesity may therefore facilitate the development of targeted public health strategy. This study aimed to determine the views of South Asian mothers regarding childhood obesity.

Methods A purposive sampling strategy was used to identify mothers of children aged 3-11 years of South Asian origin attending a childrens' day centre in Bradford, UK. Eligible mothers were consented for participation in semi-structured in-depth interviews regarding childhood obesity. Interviews were facilitated by an experienced qualitative researcher in the presence of a dedicated translator. All conversations were electronically recorded and independently reviewed for retrospective quality control. Thematic and content analysis was applied in order to generate coding themes for analysis in order to facilitate indexing and summarisation of key data.

Results A total of 14 mothers, aged $32.4 \pm 6$ years were interviewed. Thematic and content analysis generated four distinct themes: 1) perception of childhood obesity; 2) implications for long-term health; 3) awareness of preventative measures; and 4) barriers to prevention. Participants reported reasonable awareness of obesity as a risk factor for future health problems but knowledge of specific disease states was limited. Understanding of contributory risk factors including diet was high; however awareness of exercise as a preventative measure was poor with only $7 \%$ of participants reporting their children to be involved in regular exercise. Despite this finding, 50\% felt that their children gained enough exercise. Knowledge of locally available interventions including healthy eating schemes and extra-curricular activities was highly variable with first-generation migrants displaying a complete lack of awareness.

Conclusions This study highlights a lack of awareness of preventative measures in addition to poor knowledge of available interventions. This suggests a need for promoting culturally sensitive obesity education and intervention planning in partnership with families of South Asian origin, especially amongst firstgeneration migrants. 